\title{
Article \\ Service Restoring Reconfiguration for Distribution Networks Considering Uncertainty in Available Information
}

\author{
Hirotaka Takano $^{1, *}$, Junichi Murata ${ }^{2}$, Kazuki Morishita ${ }^{1}$ and Hiroshi Asano ${ }^{1,3}$ \\ 1 Department of Electrical, Electronic and Computer Engineering, Gifu University, Gifu 501-1193, Japan; \\ z4526063@edu.gifu-u.ac.jp (K.M.); hasano@gifu-u.ac.jp (H.A.) \\ 2 Department of Electrical Engineering, Kyushu University, Fukuoka 819-0395, Japan; \\ murata@cig.ees.kyushu-u.ac.jp \\ 3 Energy Innovation Center, Central Research Institute of Electric Power Industry, Kanagawa 240-0196, Japan \\ * Correspondence: takano@gifu-u.ac.jp; Tel.: +81-58-293-2720
}

check for updates

Citation: Takano, H.; Murata, J.; Morishita, K.; Asano, H. Service Restoring Reconfiguration for Distribution Networks Considering Uncertainty in Available Information Appl. Sci. 2021, 11, 4169. https:// doi.org/10.3390/app11094169

Academic Editor: Hannu Laaksonen

Received: 29 March 2021

Accepted: 29 April 2021

Published: 2 May 2021

Publisher's Note: MDPI stays neutra with regard to jurisdictional claims in published maps and institutional affiliations.

Copyright: (c) 2021 by the authors. Licensee MDPI, Basel, Switzerland. This article is an open access article distributed under the terms and conditions of the Creative Commons Attribution (CC BY) license (https:// creativecommons.org/licenses/by/ $4.0 /)$.

\begin{abstract}
The recent growth in the penetration of photovoltaic generation systems (PVs) has brought new difficulties in the operating and planning of electric power distribution networks. This is because operators of the distribution networks normally cannot monitor or control the output of the PVs, which introduces additional uncertainty into the available information that operations must rely on. This paper focuses on the service restoration of the distribution networks, and the authors propose a problem framework and its solution method that finds the optimal restoration configuration under extensive PV installation. The service restoration problems have been formulated as combinatorial optimization problems. They do, however, require accurate information on load sections, which is impractical in distribution networks with extensively installed PVs. A combined framework of robust optimization and two-stage stochastic programming adopted in the proposed problem formulation enables us to deal with the PV-originated uncertainty using readily available information only. In addition, this problem framework can be treated by a traditional solution method with slight extensions. The validity of the authors' proposal is verified through numerical simulations on a real-scale distribution network model and a discussion of their results.
\end{abstract}

Keywords: distribution networks; distribution network reconfiguration; service restoration; restoration configuration; robust optimization; two-stage stochastic programming; treatment of uncertainty

\section{Introduction}

An electric power distribution network is constructed by distribution substations, distribution feeders, circuit breakers and interconnecting and sectionalizing switches. Historically, the distribution feeders, e.g., $6.6 \mathrm{kV}$ feeders in Japan, have been expanded radially from the distribution substations to supply power to spreading power-consuming areas. The distribution feeders are divided into several load sections by the sectionalizing switches and each of the load sections is connected to multiple other feeders via the interconnecting switches. By closing or opening the switches appropriately, the distribution network can take different radial network topologies with a substation at its center. This is the multi-sectionalized and multi-connected distribution network [1].

When situations such as power failure in the distribution network arise, the operators flip states of the switches to reform the distribution network from its original radial configuration to another one, which is the distribution network reconfiguration. Finding an appropriate set of the switch states is traditionally formulated as a combinatorial optimization problem and familiar in the electrical power field. The service restoration problem, which is to minimize outage loads in restorative phases [2-6], is well known as a typical example of a problem of distribution network reconfiguration. In addition, traditional and/or intelligent optimization algorithms have been applied to solve the reconfiguration problems. Dual-gradient methods [7], branch exchange methods [8-10] 
and simplex methods [11] are included in the former, while metaheuristics [12-15] and artificial neural networks $[16,17]$ are in the latter. However, there is no established solution method for distribution network reconfiguration since distribution networks have a large number of switches.

The recent growth in the penetration of photovoltaic generation systems (PVs) brings new challenges to distribution network reconfiguration [18,19]. The output of the PVs strongly depends on weather conditions and cannot be monitored or controlled by the distribution network operators. Moreover, PVs connected to the outage load sections must be normally isolated from the distribution network to prevent their islanding operations $[20,21]$. Most of the traditional service restoration problems require accurate information of the load sections, including the status of the PVs, while the PV installation is accompanied by additional uncertainty in the measurement and estimation of the section loads [22-25]. That is, we cannot remove the uncertainty-originated operational risks of the overload and the voltage limit violation in the determined "optimal" restoration configuration. For these reasons, extended problem frameworks of the distribution network reconfiguration, which include applications of stochastic frameworks [26-28], have been attracting attention.

This paper presents a problem framework and its solution method that finds the optimal restoration configuration under extensive PV installation. In the problem formulation, the application of robust optimization and two-stage stochastic programming enables us to deal with uncertainty using readily available information only. The robust optimization often gives conservative solutions. To mitigate this, the two-stage stochastic programming is combined with it. A parameter, the confidence coefficient, controls how they are combined. A particular value of this parameter turns the combined method to pure robust optimization. Furthermore, a solution method for the formulated problem is presented. Finally, the validity of the authors' proposal is verified through numerical simulations on a real-scale distribution network model and includes a discussion of their results.

\section{Service Restoration Procedure}

Distribution networks are designed radially, and the power flow is controlled by the states of the circuit breakers and the interconnecting and sectionalizing switches. Figure 1 illustrates a simplified model of distribution networks. In Figure 1, the distribution feeder is divided into three load sections by three sectionalizing switches, and each load section is connected to another feeder through an interconnecting switch. This is the three-sectionalized and three-connected distribution network, which is one of the most reliable structures of the multi-sectionalized and multi-connected distribution networks [1]. Some switches cannot be operated remotely, and they are excluded from our discussion.

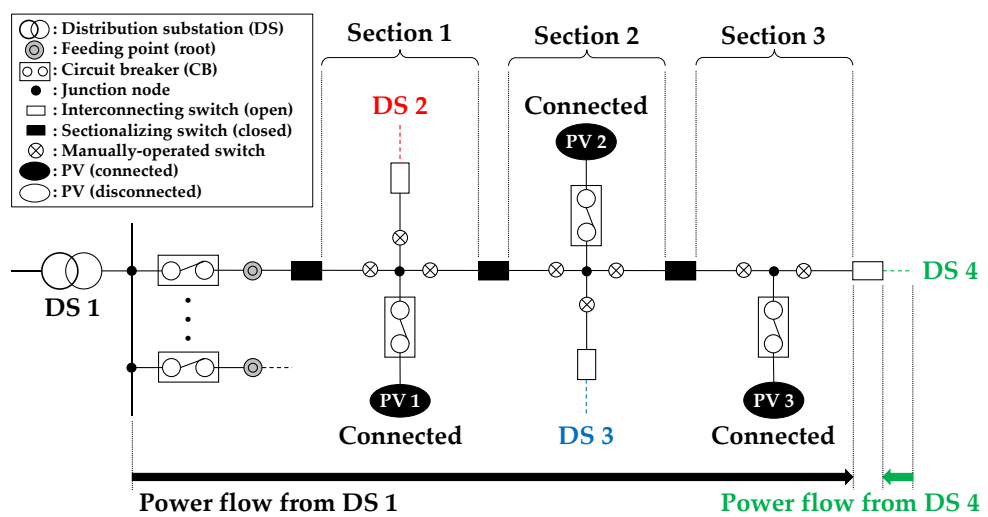

Figure 1. Distribution network model (normal condition).

In normal operating conditions, the states of the switches are decided to maintain the power supply reliability and power quality. Once trouble occurs in the distribution 
network, the resulting outage leads to significant impacts on activities in society. This is the strongest reason why the distribution network operators are required to immediately resume the service to as many customers as possible. Figure 2 illustrates an example of distribution network reconfiguration during the service restorative phases.

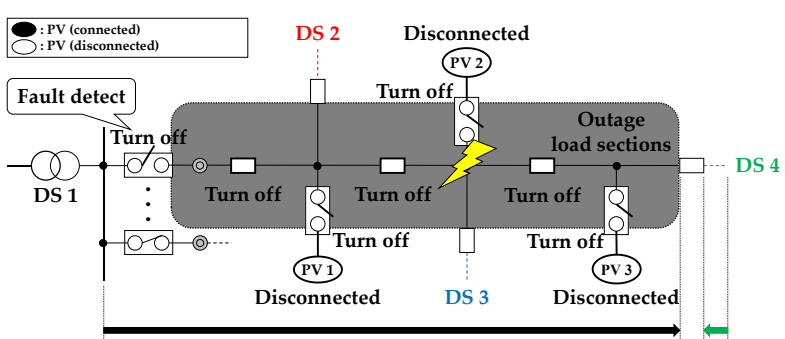

(a)

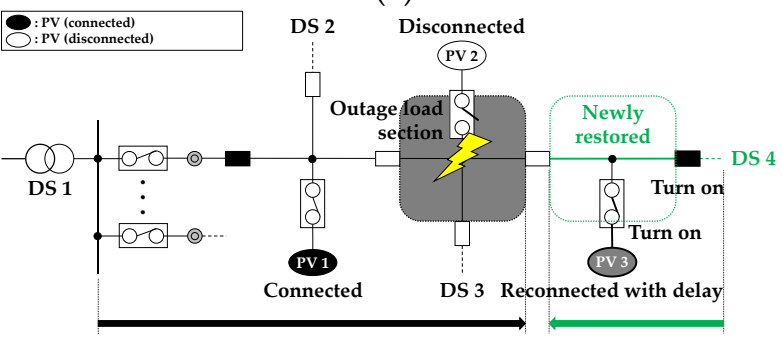

(c)

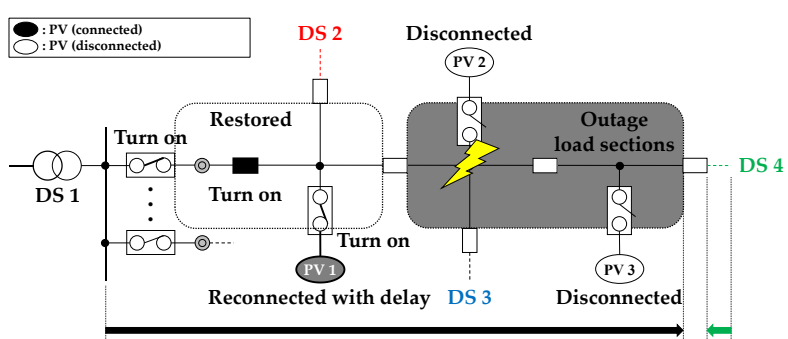

(b)

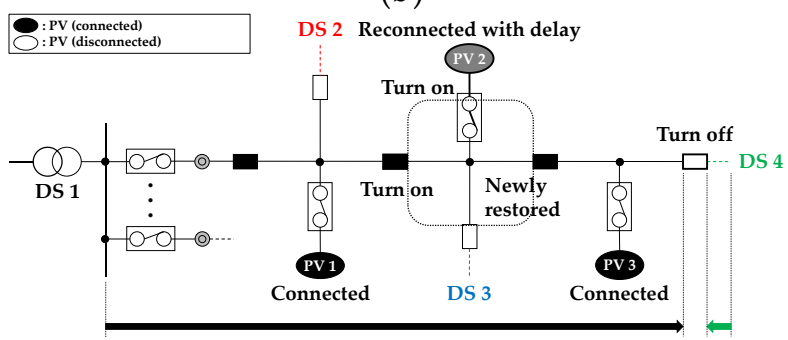

(d)

Figure 2. Service restoration procedure: (a) fault isolation (emergency condition); (b) fault identification and service reactivation (restorative phase); (c) service restoration by load transfer (restorative phase); (d) PV reconnection after fault clearing (normal condition).

As illustrated in Figure 2a, after detecting a fault, the distribution feeder with the faulty load section is isolated automatically by turning off a circuit breaker and sectionalizing switches. In Figure 2b, the circuit breaker and the sectionalizing switches turn on, sequentially starting from the circuit breaker toward the sectionalizing switches adjacent to the faulty load section. In this step, the faulty load section is identified. Next, as shown in Figure $2 c$, the interconnecting switches are operated to reactivate the power supply from other distribution feeders to as many outage sections as possible. Then, the distribution network returns to its original configuration after clearing the fault as shown in Figure 2d, which is the same as Figure 1 when no PVs are installed.

On the other hand, the power flow conditions in Figures 1 and $2 \mathrm{~d}$ are different if the PVs feed the power to the distribution feeders. In the emergency condition, the PVs connected to the isolated feeders are simultaneously disconnected to prevent their islanding operations. As shown in Figure 2b,c, the disconnected PVs automatically return to the distribution network but with time delays. Even after the distribution network has returned to its original configuration, as shown in Figure 2d, the distribution substation must supply extra power to compensate for the shortage of power caused by the delayed reconnection of PVs. However, the distribution network operators cannot know the reconnection status because it is not monitorable or controllable. In summary, the uncertainty caused by the unknown time delays leads to difficulty in estimating the amount and duration of extra power supply, and therefore, the service restoration problems become more complicated.

\section{Problem Formulation}

During the restorative phases, the distribution network operators decide whether each switch is to be open or closed. This problem is formulated as a combinatorial optimization problem, and its optimization variables are defined as

$$
x_{h} \in\{0,1\}, \text { for } h \in W,
$$


where $x_{h}$ is the $0-1$ variable of switch $h$ (0: open, 1 : closed) and is an element of the vector $x$, and $W$ is the set of switch numbers.

In this section, the frameworks of traditional and proposed service restoration problems are presented.

\subsection{Formulation of Traditional Service Restoration Problems}

The top priority in the emergency condition is to immediately resume service to as many outage consumers as possible $[2-7,12,15,23-25]$. Therefore, the service restoration problem is formulated as an optimization problem in terms of minimizing the weighted sum of the total amount of outage loads and the number of switching operations. The objective function is represented as

$$
\begin{gathered}
\min _{x} f(x), \\
f(x)=\sum_{j \in S^{\prime}(x)}\left|I_{j}\right|+\alpha \sum_{h \in W}\left|x_{h}-x_{h}^{*}\right|,
\end{gathered}
$$

where $I_{j}$ is the net load of section $j, x_{h}^{*}$ is the switch state in the initial configuration, $S^{\prime}(x)$ is the set of unrestored section numbers and $\alpha$ is the weighting factor $\left(\sum_{j \in S^{\prime}(x)}\left|I_{j}\right| \gg\right.$ $\left.\alpha \sum_{h \in W}\left|x_{h}-x_{h}^{*}\right|\right)$.

The load sections must, unless they are unrestorable, satisfy the following operational constraints:

$$
\begin{gathered}
\sum_{i \in F} y_{i, j}(x)=1, \text { for } j \in S \backslash S^{\prime}(x), \\
\left|\sum_{j^{\prime} \in L_{i, j}}\left(I_{j^{\prime}} y_{i, j^{\prime}}(x)\right)\right| \leq C_{j} \text {, for } i \in F, j \in S \backslash S^{\prime}(x), \\
\underline{V_{j}} \leq V_{i}-\sum_{j^{\prime \prime} \in H_{i, j}}\left[Z_{j^{\prime \prime}} \sum_{j^{\prime} \in L_{i, j^{\prime \prime}}}\left(I_{j^{\prime}} y_{i, j^{\prime}}(x)\right)\right] \leq \overline{V_{j}}, \text { for } i \in F, j \in S \backslash S^{\prime}(x),
\end{gathered}
$$

where $y_{i, j}(x)$ is the $0-1$ variable that indicates whether section $j$ receives power from feeding point (the root of feeder) $i$ under the switch status $x, V_{i}$ is the sending voltage of feeder $i$, $Z_{j}$ is the line impedance of section $j, C_{j}$ is the line capacity of section $j, \overline{V_{j}}$ and $V_{j}$ are the upper and lower voltage limits in section $j, F$ is the set of feeder numbers, $S$ is the set of section numbers, $L_{i, j}$ is the set of section numbers starting from section $j$ toward the end of feeder $i$ and $H_{i, j}$ is the set of section numbers from the root of the feeder toward section $j$.

Equation (4) restricts the distribution network configuration radially, and the others respectively represent acceptable ranges of the line current and voltage.

\subsection{Proposed Treatment of Uncertainty}

In the actual distribution network operations, the net loads $I_{j}$ are given as

$$
I_{j}=I_{j}^{*}+P V_{j}^{*}, j \in S,
$$

where $I_{j}^{*}$ is the true value of the section load of section $j$ and $P V_{j}^{*}$ is the true value of PV outputs of section $j$, which is treated as a negative load.

If the distribution network operators knew the values of $I_{j}^{*}$ and $P V_{j}^{*}$, the traditional optimal configuration would restore the service without any constraint violations. However, this is not the case, since the operators do not have access to the section loads or the PV outputs in each load section. The only available information is their sum: the net loads $I_{j}$. In addition, in the middle of fault, no power is supplied, and thus the net loads or the net "demands" to be exact, are not measurable. So, they are approximated by the net loads $I_{j}^{\prime}$, measured just before the fault occurrence, which consist of unmeasurable section loads 
$I_{j}^{\prime *}$ and the unmeasurable PV output $P V_{j}^{\prime *}$ just before the fault occurrence, as shown in (8) below.

$$
I_{j}^{\prime}=I_{j}^{*}+P V_{j}^{\prime *}, j \in S .
$$

Although the distribution network operators do not have the true values of the PV outputs, their specifications, connection points and historical output records are available. By using this information, the possible range of the PV outputs can be set as

$$
P V_{j}^{\prime *} \in\left[0, P V_{j}^{\max }\right], j \in S,
$$

where $P V_{j}^{\max }$ is the assumable maximum value of PV outputs of section $j$.

Based on (8) and (9), we can set the variation range of $I_{j}^{\prime}$, and thus the robust optimization and the two-stage stochastic programming are applicable to the service restoration problem in this study.

\subsection{Proposed Problem Formulation}

Robust optimization is an optimization framework in which a certain measure of robustness is sought against uncertainty, represented as variability in the variables [29-32]. However, robust optimization has a significant drawback in that its solutions are highly conservative. This is because it seeks the solution that is feasible whatever the uncertainty is, or equivalently, the solution that is feasible in the worst-case scenario. On the other hand, two-stage stochastic programming is well known as a typical stochastic programming and treats the impact of uncertainty as an additional cost [33-35]. In two-stage stochastic programming, the minimum cost that is additionally necessary to deal with the constraint violations, which is the recourse function, is calculated and then aggregated into the original objective function in the first stage. Afterward, the additional cost is minimized in the second stage.

Here we regard the PV outputs as the stochastic variables and assume their likely ranges as

$$
\widetilde{P V_{j}} \in\left[0, \xi P V_{j}^{\max }\right], j \in S,
$$

where $\widetilde{P V}_{j}$ is the stochastic PV output and an element of the vector of $\widetilde{P V}$ and $\xi$ is the confidence coefficient $(\in[0,1])$.

In theory, $\widetilde{P V}$ can take any positive value up to $P V_{j}^{\max }$. We, however, assume that the distribution network operators have confidence that the value is included in the smaller range of (10). Variation sets of the section loads are represented as

$$
\begin{gathered}
U_{j}=\left\{I_{j} \mid I_{j}^{\text {low }} \leq I_{j} \leq I_{j}^{\text {high }}\right\}, j \in S, \\
\left\{\begin{array}{l}
I_{j}^{\text {low }}=I_{j}^{\prime}-\xi P V_{j}^{\max } \\
I_{j}^{\text {high }}=I_{j}^{\prime}+\xi P V_{j}^{\max }
\end{array}\right.
\end{gathered}
$$

The constraint violations caused by the uncertainty are, when they occur, eliminated by additional switch operations, which leads to extra power outage that is the cost or recourse function we have to pay to deal with uncertainty. Now, the objective function is reformulated as

$$
\begin{gathered}
f(x)=f_{0}(x)+E_{\widetilde{P V}}[Q(x, \widetilde{P V})], \\
f_{0}(x)=\sum_{j \in S^{\prime}(x)}\left(\max _{\widetilde{P V} \in\left[0, \tilde{P} V_{j}^{\max }\right]}\left|I_{j}^{\dagger}\right|\right)+\alpha \sum_{h \in W}\left|x_{h}-x_{h}^{*}\right|, \\
E_{\widetilde{P V}}[Q(x, \widetilde{P V})]=\int_{\tilde{\zeta} P V_{k}^{\max }}^{P V_{k}^{\max }}\left\{\sum_{k \in S^{\prime}\left(x, P V_{k}^{+}\right)}\left(\left|I_{k}^{+}+P V_{k}^{\dagger}\right| \cdot c_{k}\left(P V_{k}^{\dagger}\right)\right)\right\} \mathrm{d} P V_{k}^{+},
\end{gathered}
$$


where $I_{j}^{\dagger}$ is the realization value of the section load of section $j, P V_{j}^{\dagger}$ is the realization value of the PV output of section $j, c_{j}\left(P V_{j}^{+}\right)$is the probability distribution of the PV output of section $j$ and $S\left(x, P V_{j}^{+}\right)$is the set of extra unrestored loads of section $j$.

Robust optimization deals with the uncertain PV output $P V_{j}^{\prime *}$ in the range of $\left[0, \xi P V_{j}^{\max }\right]$, and the first term of (14) expresses its worst-case load outage. Beyond this range of uncertain PV output, i.e., in the range of $\left(\xi P V_{j}^{\max }, P V_{j}^{\max }\right]$, the two-stage stochastic programming takes over as shown in (15).

The operational constraints (5) and (6) are redefined as

$$
\begin{gathered}
\left\{\begin{array}{c}
\sum_{j^{\prime} \in L_{i, j}}\left(-I_{j^{\prime}}^{\mathrm{low}} y_{i, j^{\prime}}(x)\right) \leq C_{j} \\
\left.\sum_{j^{\prime} \in L_{i, j}} I_{j^{\prime}}^{\mathrm{high}} y_{i, j^{\prime}}(x)\right) \leq C_{j}
\end{array}, \text { for } i \in F, j \in S \backslash S^{\prime}(x),\right. \\
\left\{\begin{array}{c}
V_{j} \leq V_{i}-\sum_{j^{\prime \prime} \in H_{i, j}}\left[Z_{j^{\prime \prime}} \sum_{j^{\prime} \in L_{i, j^{\prime \prime}}}\left(I_{j^{\prime}}^{\mathrm{low}} y_{i, j^{\prime}}(x)\right)\right] \\
V_{i}-\sum_{j^{\prime \prime} \in H_{i, j}}\left[Z_{j^{\prime \prime}} \sum_{j^{\prime} \in L_{i, j^{\prime \prime}}}\left(I_{j^{\prime}}^{\text {high }} y_{i, j^{\prime}}(x)\right)\right] \leq \overline{V_{j}}
\end{array}, \text { for } i \in F, j \in S \backslash S^{\prime}(x) .\right.
\end{gathered}
$$

The remarkable feature of the proposed formulation is that the problem framework can switch to pure robust optimization when we set the confidence coefficient $\xi$ to 1 . A smaller confidence relaxes the conservativeness and brings more alternatives into the distribution network operations. However, too small a confidence coefficient increases uncertainty-originated risks, and therefore, it is important to set its value in consideration of the balance of power supply reliability and operational efficiency.

\section{Solution Method}

Since the distribution networks generally have a large number of switches, it is impossible to enumerate all possible solution candidates (sets of switch states) and select the optimal solution from them. For example, with 100 switches, the number of possible solution candidates is $2^{100}\left(\simeq 1.27 \times 10^{30}\right)$. In this paper, an enumeration-based method is extended to solve the formulated problem.

\subsection{Basis of Solution Method}

The authors have proposed an enumeration-based solution method for the distribution network reconfiguration $[23,25,36]$. In these methods, first, the target distribution network is partitioned into several groups. Each group consists of load sections and switches that share the common relevant feeding points which can supply them with power without violating the radiality constraint. Second, all of the partial radial candidates, namely, all the radial configurations within each group, are exactly enumerated. Third, partial radial candidates satisfying the constraints of the line capacity and voltage range are extracted from each group as part of feasible solution candidates. Fourth, all of the possible combinations of the extracted partial candidates are constructed and then evaluated as configuration candidates for the whole distribution network. Finally, we can obtain the optimal configuration of the distribution network.

The previously proposed methods are applicable only when the structure of the target distribution network is simple, but their solutions have global optimality. Owing to this feature, the enumeration-based methods help exact comparison in the different problem frameworks, and this is the reason why the authors select them as the basis of the solution method.

\subsection{Proposed Solution Method}

The solution procedure of the distribution network reconfiguration is summarized in the following four steps: in Step 1, the radial configuration candidates are generated, in Step 2, the constraint violations of the line capacity and voltage limit are evaluated, in 
Step 3, the objective function is calculated, and in Step 4, the optimal (or quasi-optimal) configuration is determined. When $\xi$ is appropriately set and the corresponding uncertainty ranges (12) are given, the difference between the traditional service restoration problems and the extended one is only in the objective functions. Therefore, as indicated in Figure 3, we can extend the previously proposed method without any complicated procedure and apply it as the solution method for the proposed problem framework. Figure 4 shows a conceptual illustration of the difference in feasible solutions between the traditional problem frameworks and the proposed one. For further details of the solution method, refer to the references.

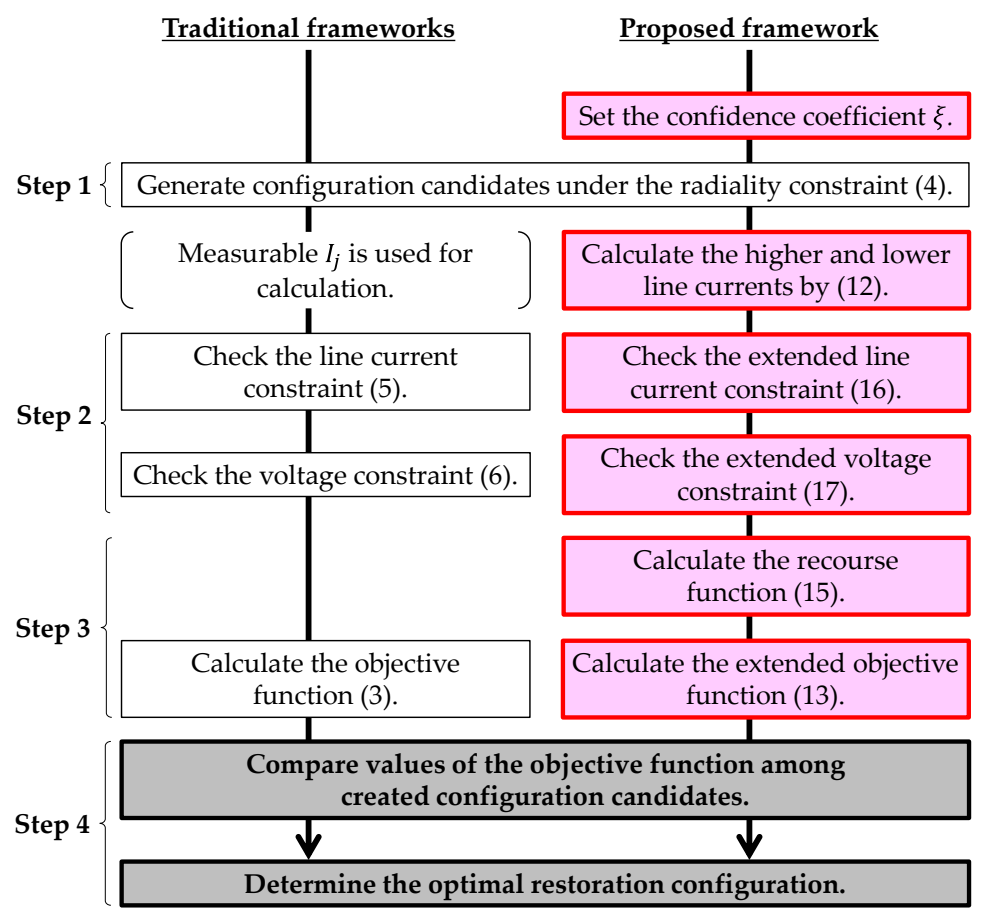

Figure 3. Procedure of solution methods.

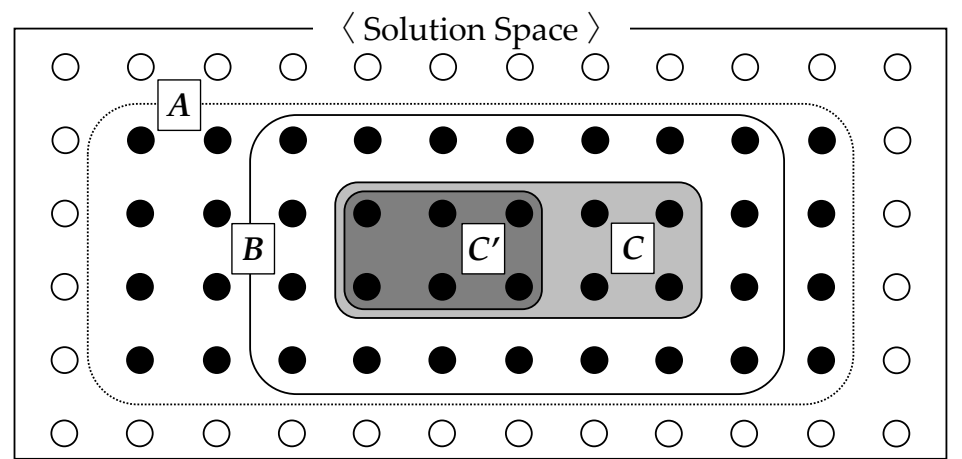

$\bigcirc$ : Infeasible candidates

: Radial candidates

$A$ : Set of radial candidates.

$B$ : Set of feasible candidates in the traditional frameworks.

$C$ : Set of feasible candidates in the proposed framework $(\xi<1)$.

$C^{\prime}$ : Set of feasible candidates in the proposed framework $(\xi=1)$.

Figure 4. Difference in feasible solutions between traditional and proposed frameworks.

The difficulty in the distribution network reconfiguration is to identify feasible candidates among a huge number of possibilities and find the optimal one $[37,38]$. If the distribution network can be partitioned into groups as described in Section 4.1, the iden- 
tification of radial configuration candidates is not difficult. Otherwise, some intelligent optimization algorithms with an appropriate penalty term added to the objective function will be useful.

\section{Numerical Simulations}

Figure 5 illustrates an actual-scale distribution network model, which was made by referring to an actual operating underground and overhead intermingled distribution network in Japan [37,39]. This model can be divided into groups as described in Section 4.1, and thus the enumeration-based method was used to solve both of the problems in the traditional and proposed frameworks. In the proposed framework, the two values of $\xi$, 0.7 and 1.0, were used, corresponding to the combined robust optimization and two-stage stochastic programming problem and the pure robust optimization problem, respectively. Through comparisons among these results, the validity of the authors' proposal was verified.

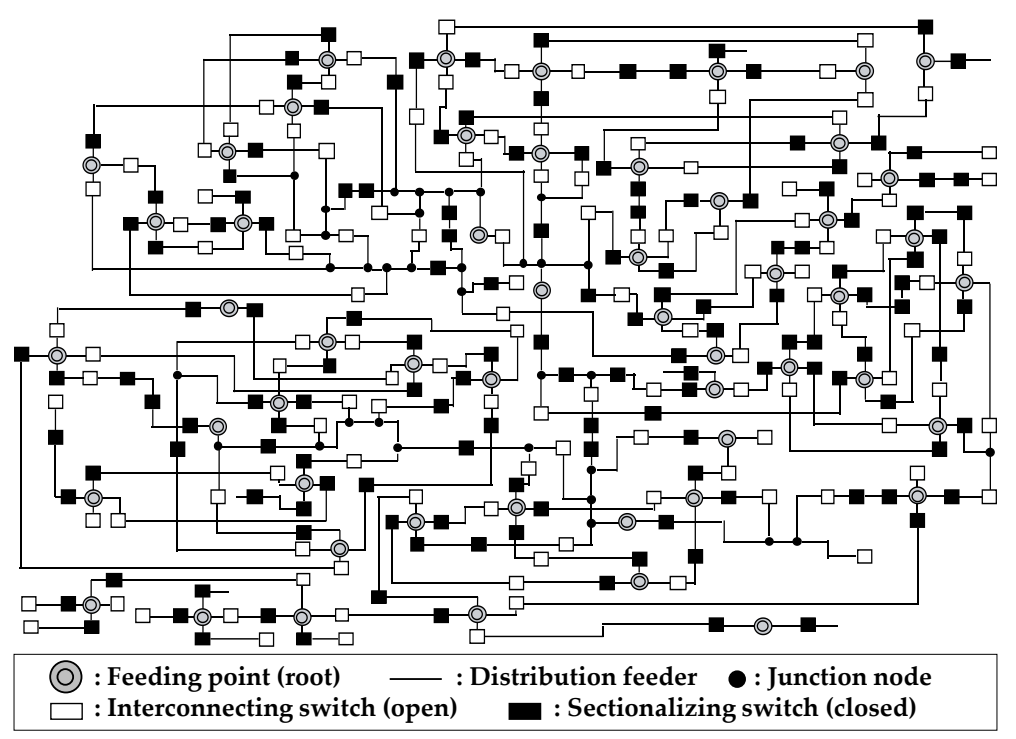

Figure 5. Numerical simulation model.

\subsection{Conditions of Numerical Simulations}

In the numerical simulations, the following scenario was assumed: one feeding point is supplying 3.78 MW of power to the largest-consuming area where PVs are connected, the total capacity of the PVs in the area is approximately equal to $30 \%$ of the total load of the area, the PVs are generating power equal to $55 \%$ of the total PV capacity and the feeding point has a fault and stops supplying power. Since the distribution network operators do not know the actual PV outputs (0.72 MW) nor the actual load (3.78 MW), they have to restore the service relying on the measured section loads (3.14 MW) in the target area. Table 1 summarizes these conditions, and Figure 6 displays the line currents in the normal condition. Figure 7 shows the conditional probability distribution of PV output given by its output prediction, which was calculated by referring to the predicted and the actual PV outputs measured from 1 June 2011 to 31 May 2012 in Japan [40]. 
Table 1. Specification of Figure 5.

\begin{tabular}{lc}
\hline Total number of distribution substations & 3 \\
Total number of feeding points & 53 \\
Total number of switches & 266 \\
Total number of all configuration candidates & $1.19 \times 10^{80}$ \\
Total amount of section loads & $30.97 \mathrm{MW}$ \\
Total amount of measured outage loads & $3.14 \mathrm{MW}$ \\
Total amount of PV capacities in target area & $1.32 \mathrm{MW}$ \\
Total amount of actual PV outputs in target area & $0.72 \mathrm{MW}$ \\
\hline
\end{tabular}

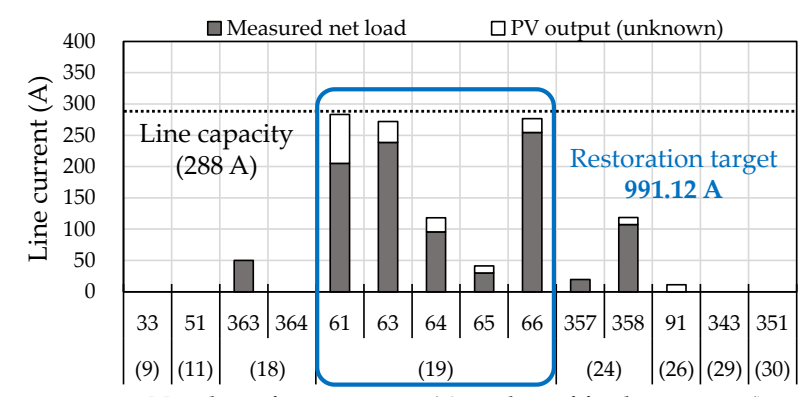

Figure 6. Line currents in normal condition.

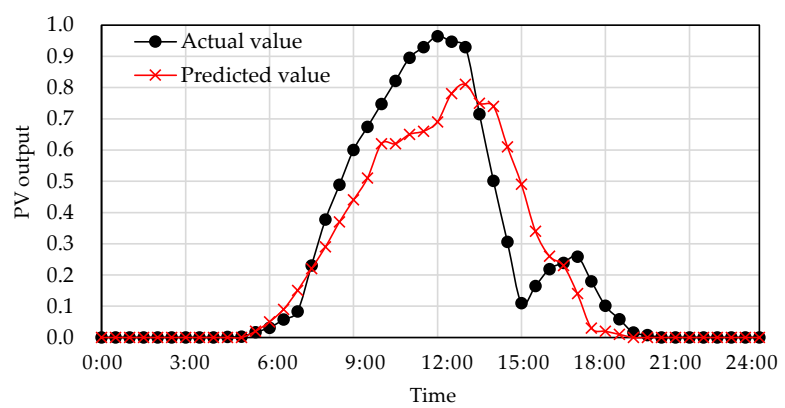

(a)

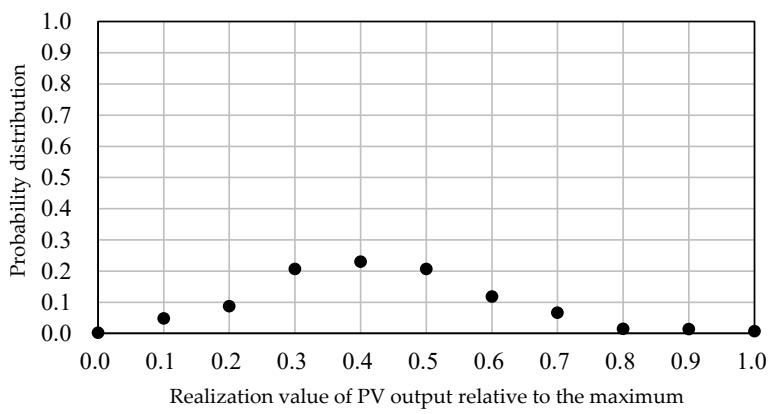

(b)

Figure 7. PV output and its probability distribution: (a) sample of actual and predicted PV outputs; (b) probability distribution for assumed PV output (55\% of PV capacity).

\subsection{Results and Discussions}

Table 2 summarizes the globally optimal solutions of the traditional and proposed frameworks. Figure 8 illustrates the line currents in each restoration configuration.

Table 2. Comparison of numerical simulation results.

\begin{tabular}{lccc}
\hline \multicolumn{1}{c}{ Comparison Index } & Traditional & Two-Stage Stochastic Programming \\
& Framework & $\boldsymbol{\xi}=\mathbf{0 . 7}$ & $\boldsymbol{\xi}=\mathbf{1 . 0}$ \\
\hline Estimated total outage loads & $206.57 \mathrm{~kW}$ & $248.45 \mathrm{~kW}$ & $260.98 \mathrm{~kW}$ \\
Expected value of extra outage loads & - & $1.11 \mathrm{~kW}$ & 0 \\
Number of changes of switch states & $10(5$ pairs $)$ & $12(6$ pairs $)$ & $14(7$ pairs $)$ \\
\hline
\end{tabular}

As summarized in Table 2, different configurations were selected, although each problem framework judged that its optimal solution could restore all outage loads excluding those in the load sections directly connected to the faulty feeding point. The number of changes of the switch states in the traditional framework was the smallest; however, as shown in Figure 8a, the overload occurred by the extra power supply necessary to compensate the disconnected PVs. In Figure 8c, which shows the result of pure robust 
optimization, there is no operational constraint violation in exchange for an increase in the number of changes of the switch states. On the other hand, Figure $8 \mathrm{~b}$ shows characteristics intermediate between the above two frameworks. It indicates that the relaxation of conservativeness, namely, setting $\xi=0.7$ rather than $\xi=1.0$, brought a decrease in the number of changes of the switch states. In Figure 8b, the PV-originated uncertainty $(\geq \xi)$ was reflected in the expected value of extra outage loads.

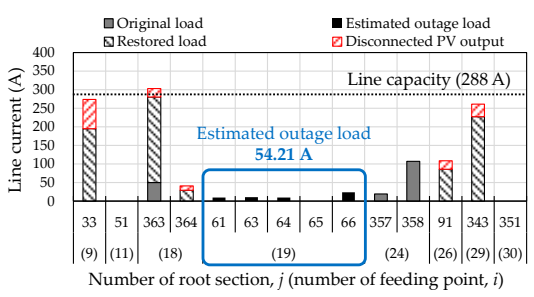

(a)

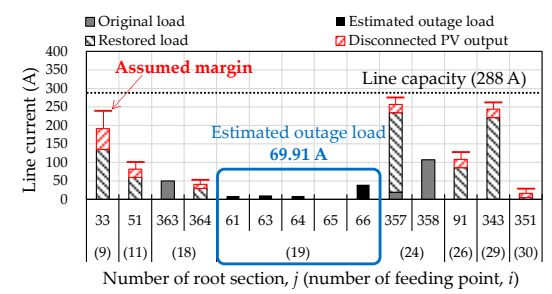

(b)

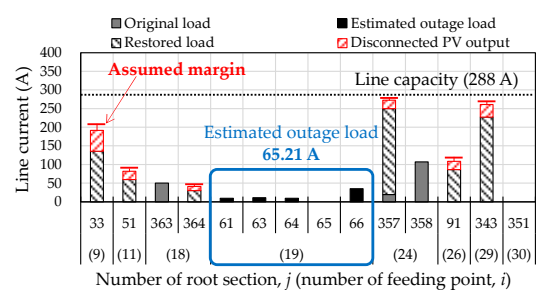

(c)

Figure 8. Line currents in each restoration configuration: (a) traditional framework; (b) proposed framework $(\xi=0.7)$; (c) robust optimization framework $(\xi=1.0)$.

The authors carried out several numerical simulations under different conditions, and as a result, found that the solutions derived in the traditional framework can cause operational constraint violations. For example, when we increased the level of PV penetration, the PV-originated uncertainty was intensified, associated with (10-12), and it brought more violations to the optimal solution of the traditional framework. In this section, the typical results were shown to discuss the possibility of constraint violations by the traditional framework in a realistic situation. Under these circumstances, we can conclude that the proposed problem framework and its solution method functioned appropriately.

\section{Conclusions}

This paper presented a problem framework and its solution method that finds the optimal restoration configuration of distribution networks considering the PV penetration. In the proposed problem formulation, robust optimization and two-stage stochastic programming were applied to the service restoration problem to treat uncertainty as the potential risk of operational constraint violations. As a result, the proposed framework gives a reliable solution for PV-originated uncertainty using only the available information in the service restoration. In the proposed framework, the setting of the confidence coefficient has a significant impact on power supply reliability and also affects operational efficiency because the larger coefficient brings more switching operations.

Through numerical simulations and the discussion of their results, the authors showed the possibility that traditional frameworks lead to solutions with overload and voltage limit violation. We also verified that the balance of reliability and efficiency depended on the setting of the confidence coefficient. In future work, the authors will find a guideline for the appropriate setting of the confidence coefficient.

Author Contributions: Conceptualization, H.T. and J.M.; methodology, H.T., K.M. and J.M.; software, K.M.; validation, H.T., K.M. and H.A.; writing-original draft preparation, H.T., K.M., J.M. and H.A.; writing-review and editing, H.T., J.M. and H.A.; supervision, H.T. and H.A.; project administration, H.T. All authors have read and agreed to the published version of the manuscript.

Funding: This research received no external funding.

Institutional Review Board Statement: Not applicable.

Informed Consent Statement: Not applicable.

Data Availability Statement: Not applicable.

Conflicts of Interest: The authors declare no conflict of interest. 


\section{References}

1. Takano, H.; Kawamura, K.; Iizaka, T. Industry Practice and Operational Experience of Key Distribution Applications of Smart Grid Technologies. In Smart Grid Handbook, 3 Volume Set; Liu, C.C., McAuthur, S., Lee, S.J., Eds.; John Wiley \& Sons: Hoboken, NJ, USA, 2016; pp. 967-994.

2. Liu, C.C.; Lee, S.J.; Venkata, S.S. An Expert System Operation Aid for Restoration and Loss Reduction of Distribution Systems. IEEE Trans. Power Syst. 1988, 3, 619-626. [CrossRef]

3. Shirmohammadi, D. Service Restoration in Distribution Networks via Network Reconfiguration. IEEE Trans. Power Del. 1992, 7, 952-958. [CrossRef]

4. Ucak, C.; Pahwa, A. An Analytical Approach for Step-by-Step Restoration of Distribution Systems Following Extended Outages. IEEE Trans. Power Del. 1994, 9, 1717-1723. [CrossRef]

5. Sarma, N.D.R.; Ghosh, S.; Rao, K.S.P.; Srinivas, M. Real Time Service Restoration in Distribution Networks - A Practical Approach. IEEE Trans. Power Del. 1994, 9, 2064-2070. [CrossRef]

6. Nagata, T.; Sasaki, H.; Yokoyama, R. Power System Restoration by Joint Usage of Expert System and Mathematical Programming Approach. IEEE Trans. Power Syst. 1995, 10, 1473-1479. [CrossRef]

7. Aoki, K.; Nara, K.; Itoh, M.; Satoh, T.; Kuwabara, H. A New Algorithm for Service Restoration in Distribution Systems. IEEE Trans. Power Del. 1989, 4, 1832-1839. [CrossRef]

8. Ross, D.W.; Patton, J.; Cohen, A.I.; Carson, M. New Method for Evaluating Distribution Automation and Control (DAC) Systems Benefits. IEEE Trans. Power Del. 1981, PAS-100, 2978-2986. [CrossRef]

9. Civanlar, S.; Grainger, J.J.; Yin, H.; Lee, S.S.H. Distribution Feeder Reconfiguration for Loss Reduction. IEEE Trans. Power Del. 1988, 3, 1217-1223.IE. [CrossRef]

10. Baran, M.E.; Wu, F.F. Network Reconfiguration in Distribution Systems for Loss Reduction and Load Balancing. IEEE Trans. Power Del. 1989, 4, 1401-1407. [CrossRef]

11. Glamocanin, V. Optimal Loss Reduction of Distributed Networks. IEEE Trans. Power Syst. 1990, 5, 774-782. [CrossRef]

12. Morelato, A.L.; Monticelli, A.J. Heuristic Search Approach to Distribution System Restoration. IEEE Trans. Power Del. 1989, 4 , 2235-2241. [CrossRef]

13. Chiang, H.D.; Jean, J.R. Optimal Network Reconfigurations in Distribution Systems Part 2: Solution Algorithms and Numerical Results. IEEE Trans. Power Del. 1990, 5, 1568-1574.

14. Chiang, H.D.; Jean, J.R. Optimal Network Reconfigurations in Distribution Systems Part 1: A New Formulation and A Solution Methodology. IEEE Trans. Power Del. 1990, 5, 1902-1909.

15. Toune, Y.; Fudo, S.; Genji, T.; Fukuyama, Y.; Nakanishi, Y. Comparative Study of Modern Heuristic Algorithms to Service Restoration in Distribution Systems. IEEE Trans. Power Del. 2002, 17, 173-181. [CrossRef]

16. Kim, H.; Ko, Y.; Jung, K.H. Artificial Neural-Network based Feeder Reconfiguration for Loss Reduction in Distribution Systems. IEEE Trans. Power Del. 1993, 8, 1356-1366. [CrossRef]

17. Salazar, H.; Gallego, R.; Romero, R. Artificial neural networks and clustering techniques applied in the reconfiguration of distribution systems. IEEE Trans. Power Del. 2006, 21, 1735-1742. [CrossRef]

18. Wu, Y.K.; Lee, C.Y.; Liu, L.C.; Tsai, S.H. Study of Reconfiguration for the Distribution System with Distributed Generators. IEEE Trans. Power Del. 2010, 25, 1678-1685. [CrossRef]

19. Tan, S.; Xu, J.X.; Panda, S.K. Optimization of Distribution Network Incorporating Distributed Generators: An Integrated Approach. IEEE Trans. Power Syst. 2013, 28, 2421-2432. [CrossRef]

20. Sano, M.; Kimura, R.; Takano, H.; Taoka, H.; Tsutsumi, K.; Sakata, T. A Study of Impact on Power System Stability Originated from New Islanding Detection Method in PV Systems. J. Int. Counc. Electr. Eng. 2017, 7, 214-221. [CrossRef]

21. Japan Electrotechnical Standard and Codes Committee. KEITOU RENKEI KITEI (Grid-Interconnection Code), 8th ed.; The Japan Electric Association (JEA): Tokyo, Japan, 2019. (In Japanese)

22. Popovic, D.S.; Popovic, Z.N. A Risk Management Procedure for Supply Restoration in Distribution Networks. IEEE Trans. Power Syst. 2004, 19, 221-228. [CrossRef]

23. Takano, H.; Hayashi, Y.; Matsuki, J.; Kobayashi, N. Service Restoration Method Considering Simultaneous Disconnection of Distributed Generators by One Bank Fault of Distribution System. Electron. Commun. Jpn. 2008, 91, 44-55. [CrossRef]

24. Zubo, R.H.A.; Mokrayani, G.; Rajamani, H.S.; Aghaei, J.; Niknam, T.; Pillai, P. Operation and planning of distribution networks with integration of renewable distributed generators considering uncertainties: A review. Renew. Sustain. Energy Rev. 2017, 72, 1177-1198. [CrossRef]

25. Takano, H.; Murata, J.; Sugawara, A.; Taoka, H. A Study on Service Restoration of Distribution Networks Considering Uncertainty in Data Measurements. IEEJ Trans. EIS 2017, 137, 1052-1061. (In Japanese) [CrossRef]

26. Malekpour, A.R.; Niknam, T.; Pahwa, A.; Fard, A.K. Multi-Objective Stochastic Distribution Feeder Reconfiguration in Systems with Wind Power Generators and Fuel Cells Using the Point Estimate Method. IEEE Trans. Power Syst. 2013, 28, $1483-1492$. [CrossRef]

27. Ding, F.; Mather, B. On Distributed PV Hosting Capacity Estimation, Sensitivity Study, and Improvement. IEEE Trans. Sustain. Energy 2017, 8, 1010-1020. [CrossRef]

28. Akrami, A.; Doostizadeh, M.; Aminifar, F. Optimal Reconfiguration of Distribution Network Using $\mu$ PMU Measurements: A Data-Driven Stochastic Robust Optimization. IEEE Trans. Smart Grid. 2020, 11, 420-428. [CrossRef] 
29. Ben-Tal, A.; Nemirovski, A. Robust Solutions of Uncertain Linear Programs. Oper. Res. 1999, 25, 1-13. [CrossRef]

30. Ben-Tal, A.; El Ghaoui, L.; Nemirovski, A. Robust Optimization; Princeton University Press: Princeton, NJ, USA, 2009.

31. Berstimas, D.; Brown, D.B.; Caramanis, C. Theory and Applications of Robust Optimization. SIAM Rev. 2011, 50, 464-501.

32. Garbrel, V.; Murat, C.; Thiele, A. Recent Advances in Robust Optimization: An Overview. Eur. J. Oper. Res. 2014, 235, 471-483. [CrossRef]

33. Kall, P.; Wallace, S.W. Stochastic Programming; John Wiley \& Sons: Hoboken, NJ, USA, 1994.

34. Birge, J.R.; Donohue, C.J.; Holmes, D.F.; Svintsitski, O.G. A Parallel Implementation of the Nested Decomposition Algorithm for Multistage Stochastic Linear Programs. Math. Program. 1996, 75, 327-352. [CrossRef]

35. Birge, J.R.; Louveaux, F. Introduction to Stochastic Programming; Springer Nature: Basingstoke, UK, 1997.

36. Hayashi, Y.; Matsuki, J.; Shinji, I.; Takano, H.; Muto, E.; Kobayashi, N. Determination of Loss-Minimum Configuration with Mathematical Optimality in a Three-Sectionalized Three-Connected Distribution Feeder Network. Electr. Eng. Jpn. 2009, 167, 56-65. [CrossRef]

37. Takano, H.; Murata, J.; Maki, Y.; Yasuda, M. A Study on Improvement of Tabu Search-based Determination Method for Distribution Network Configuration. J. Int. Counc. Electr. Eng. 2013, 3, 61-67. [CrossRef]

38. Inoue, T.; Yasuda, N.; Kawano, S.; Takenobu, Y.; Minato, S.; Hayashi, Y. Distribution Network Verification for Secure Restoration by Enumerating All Critical Failures. IEEE Trans. Smart Grid. 2015, 6, 843-852. [CrossRef]

39. Hayashi, Y.; Takano, H.; Matsuki, J.; Yokoyama, M. A Simple Evaluation Method for Annual $\mathrm{CO}_{2}$ Emissions Reduced by Distribution Loss Minimization. IEEJ Trans. PE 2007, 127, 1137-1144. (In Japanese) [CrossRef]

40. Ishibashi, N.; Iizaka, T.; Ohira, R.; Nakanishi, Y. An insolation forecasting method by partial least squares and confidence interval estimating method. IEEJ Trans. PE 2013, 133, 64-71. (In Japanese) [CrossRef] 